\title{
Increased Community-Associated Clostridioides difficile Infections in Quebec, Canada, 2008-2015'
}

Veronica Zanichelli, Christophe Garenc, Jasmin Villeneuve, Danielle Moisan, Charles Frenette, Vivian Loo, Yves Longtin; Québec C.difficile Infection Surveillance Program (SPIN-CD)

The annual incidence rate of community-associated Clostridioides difficile infections in Quebec, Canada, has increased by $33.3 \%$, from 0.51 (2008) to 0.68 (2015) cases $/ 100,000$ population, while incidence of healthcare-associated cases remained relatively stable. Possible causes include increased disease severity, increased antimicrobial drug use, emergence of virulent strains, and heightened physician awareness.

Clostridioides difficile infections (CDIs) are commonly acquired in healthcare settings (1). In 2003, an outbreak of CDI in the province of Quebec, Canada (population, 8.2 million), required implementation of mitigation strategies and prompted introduction of a surveillance program $(2,3)$. Afterward, incidence of healthcare-associated CDIs (HA-CDIs) in the province decreased from 13.7 cases/10,000 patient-days in 2004-2005 to $6.9 / 10,000$ patient-days in 2014-2015. Although CDIs afflict mainly hospitalized patients, recent studies report increased incidence of community-associated CDIs (CA-CDIs) (4-6). Whereas most of the focus in North America has been on HA-CDI, we describe and compare long-term trends in incidence rates for HA-CDI and CA-CDI in Quebec.

\section{The Study}

To evaluate HA-CDI and CA-CDI trends in Quebec, we performed a quasi-experimental study. We used

Author affiliations: Sir Mortimer B. Davis Jewish General Hospital, Montreal, Quebec, Canada (V. Zanichelli, Y. Longtin); Centre de Recherche du CHU de Quebec, Quebec City (C. Garenc); Institut National de Santé Publique du Québec, Quebec City, Quebec, Canada (C. Garenc, J. Villeneuve); CSSS Rivière-du-Loup, Rivière-du-Loup, Québec, Canada (D. Moisan); McGill University Health Centre, Montreal (C. Frenette, V. Loo, Y. Longtin)

DOI: https://doi.org/10.3201/eid2606.190233 prospectively collected data from the Quebec Health Ministry C. difficile Infection Surveillance Program (SPIN-CD), a mandatory surveillance program introduced in 2004 (7). As of 2018, all 90 acute-care hospitals with $\geq 1,000$ admissions annually participate in SPIN-CD. These hospitals, which represent $97 \%$ of all admissions in the province, use a centralized web portal to report HA-CDI incidence density, computed as the aggregate number of cases divided by the aggregate number of patient-days per 4-week period. CA-CDI incidence rates are expressed as the number of CA-CDIs/100,000 population as reported by the Quebec Institute of Statistics (8).

CDI is defined as diarrhea ( $\geq 3$ unformed stools in $<24$ hours with symptoms lasting $\geq 24$ hours) with no other etiology and either a positive toxigenic $C$. difficile test result or evidence of pseudomembranes during histopathologic or colonoscopic examination (9). A case is considered to be HA-CDI if symptoms appear $\geq 72$ hours after admission or $\leq 4$ weeks after discharge. A CA-CDI case is defined as illness in a hospitalized patient for whom symptoms developed within 72 hours of admission and who had not been hospitalized or received ambulatory care in the previous 4 weeks. Nonhospitalized CA-CDI case-patients and recurrences (i.e., new CDI episodes within 8 weeks of a previous episode) are not reportable to SPIN-CD. Definitions did not change during the study period. The type of laboratory assay used to detect $C$. difficile was at the discretion of each center (10).

To focus the analysis on the postepidemic period (April 2008-March 2015), we excluded data from the epidemic period (August 2004-March 2008). We used Poisson regression models on time series

${ }^{1}$ Preliminary results from this study were presented at the IDweek 2018 conference; 2018 Oct 3-7; San Francisco, California, USA (abstract no. 477). 
Table 1. Annual incidence rate of community-associated and healthcare-associated Clostridioides difficile infections in the province of Quebec, Canada, 2008-2015

\begin{tabular}{|c|c|c|c|c|c|c|c|}
\hline \multirow[b]{2}{*}{ Years } & \multicolumn{4}{|c|}{ Community-associated cases } & \multicolumn{3}{|c|}{ Healthcare- associated cases } \\
\hline & No. cases & $\begin{array}{l}\text { Mean annual } \\
\text { population }\end{array}$ & $\begin{array}{c}\text { Rate } / 100,000 \\
\text { population }\end{array}$ & $\%$ Total cases & No. cases & No. patient-days & $\begin{array}{l}\text { Rate/10,000 } \\
\text { patient-days }\end{array}$ \\
\hline $2008-2009$ & 510 & $7,764,759$ & 0.51 & 13.6 & 3,244 & $4,915,666$ & 6.60 \\
\hline 2009-2010 & 568 & $7,846,295$ & 0.56 & 15.1 & 3,206 & $4,855,739$ & 6.60 \\
\hline 2010-2011 & 619 & $7,930,943$ & 0.60 & 14.9 & 3,544 & $4,898,891$ & 7.23 \\
\hline 2011-2012 & 605 & $8,009,614$ & 0.58 & 14.1 & 3,697 & $4,927,050$ & 7.50 \\
\hline $2012-2013$ & 697 & $8,084,741$ & 0.66 & 15.9 & 3,695 & $4,941,796$ & 7.48 \\
\hline 2013-2014 & 753 & $8,150,131$ & 0.71 & 17.2 & 3,615 & $4,880,472$ & 7.41 \\
\hline $2014-2015$ & 729 & $8,209,599$ & 0.68 & 17.8 & 3,372 & $4,843,433$ & 6.96 \\
\hline
\end{tabular}

data, including trend and periodic seasonal terms to calculate incidence rate ratios (IRRs) with $95 \%$ CIs and to assess trends in CA-CDIs and HA-CDIs. We also used interrupted time series analysis with segmented regression because of a change in the level and trend in HA-CDI incidence rate from 2011 on (11). We compared the change in trends in HA-CDI and CA-CDI incidence by using Z-tests of the difference of the natural logarithm of incidence rates. We used SAS software version 9.3 (https://www. sas.com) for analyses and considered $\mathrm{p}<0.05$ to be significant.

During the study period, a total of 28,854 cases of HA-CDI $(84.5 \%)$ and CA-CDI (15.5\%) were reported. The annual number of CA-CDI cases and the proportion of CDI cases that were reported as CA-CDI increased gradually from 510 (13.6\% of HA-CDI) to 729 (17.8\% of CA-CDI) cases (Table 1). Furthermore, the CA-CDI incidence rate increased $\approx 6.5 \%$ annually and overall significantly by $33.3 \%$, from 0.51 to 0.68 cases/100,000 population (IRR per 4-week period 1.005, 95\% CI 1.004-1.006; p<0.0001) (Figure 1). By contrast, the incidence of HA-CDI did not change significantly (IRR per 4-week period 1.000, 95\% CI 0.999-1.000; $\mathrm{p}=$ 0.23). Accordingly, incidence rate trends for CA-CDI differed significantly from trends for HA-CDI (IRR 1.005, 95\% CI 1.004-1.006; $\mathrm{p}<0.0001$ ).
An inflection point in HA-CDI incidence in April 2011 was demonstrated by a significant decreasing change in trend (IRR 0.996, 95\% CI 0.994-0.998; p = 0.001). By contrast, no concomitant change occurred in the trend of CA-CDI at the inflection point (Figure 2, Table 2).

\section{Conclusions}

Although the incidence of HA-CDI has been decreasing in Canada since 2009 (12), our study suggests possible emergence of CA-CDI in the province of Quebec because the number, incidence, and proportion of reported cases have been steadily increasing since 2008 . This increased incidence contrasts markedly with the overall decreasing trend of HA-CDI incidence after April 2011.

Emergence of CA-CDI has been reported in other countries $(4-6,13)$. A 2008-2013 study in Finland reported an increase in probable CA-CDI cases at an annual rate of $4.3 \%$ compared with a concomitant decrease in HA-CDI cases at an annual rate of $8.1 \%(4)$. In the United Kingdom, an analysis of hospital administrative data detected an increase in the proportion of CDI cases that were community acquired, from $7 \%$ in 1998 to $13 \%$ in 2010, while the overall incidence of CDI cases fell to less than half of peak rate (13). The US Veterans

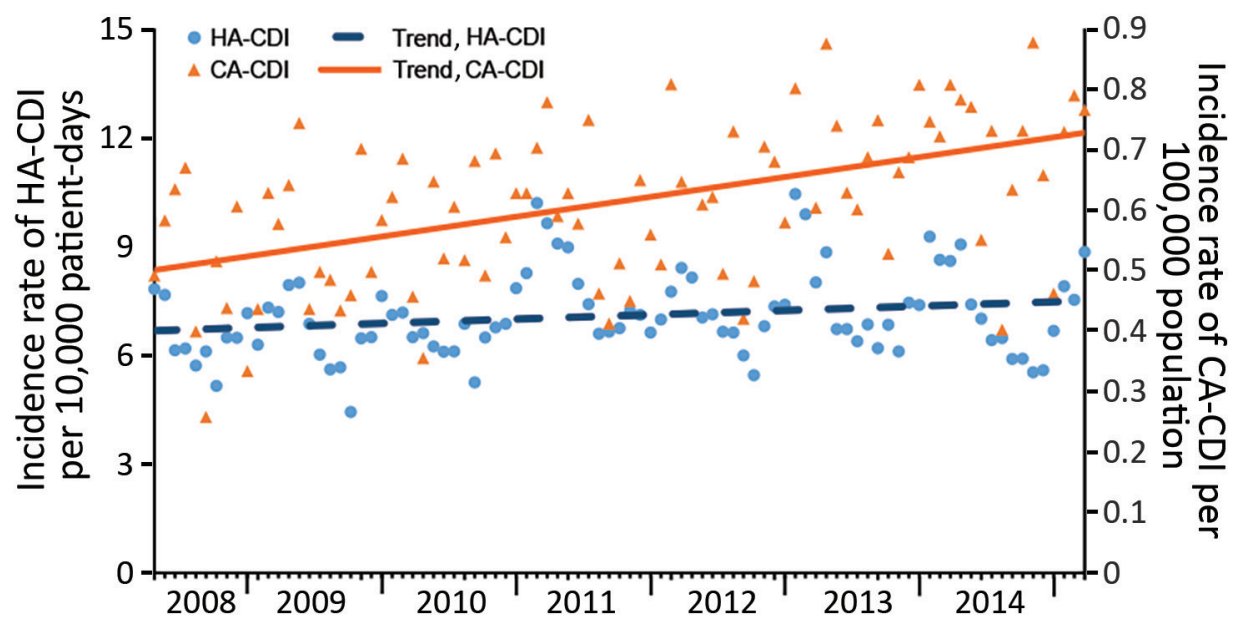

Figure 1. Incidence density of HA-CDIs and CA-CDIs per 4-week period, according to standardized surveillance definitions, Quebec, Canada, April 2008-March 2015. CDI, Clostridioides difficile infection; CA-CDI, communityassociated $\mathrm{CDI}$; HA-CDI, healthcare-associated CDI. 


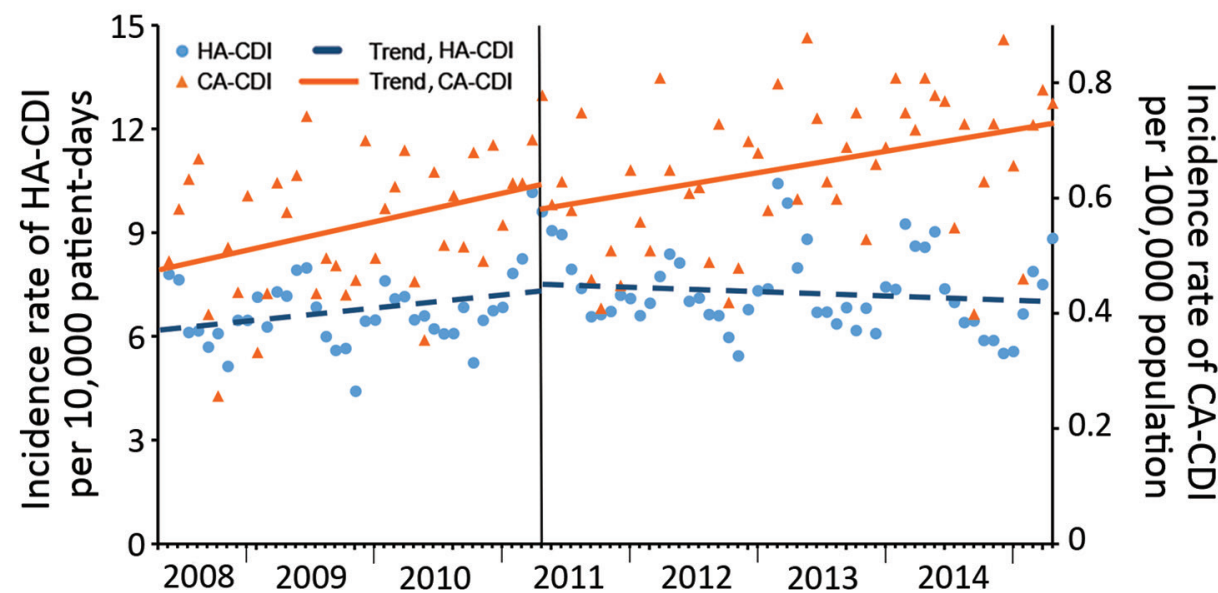

Figure 2. Trends in incidence of HA-CDIs and CA-CDls analyzed by using linear segmented regression (inflection point of HA-CDI in April 2011) per 4-week period, according to standardized surveillance definitions, Quebec, Canada, April 2008-March 2015. CDI, Clostridioides difficile infection; CA-CDI, community-associated CDI; HA-CDI, healthcareassociated CDI.

Healthcare Administration reported similar findings of an increased proportion of CDI cases that were community-associated (from $8.3 \%$ in 2003 to $26.7 \%$ in 2014) (5). Electronic patient records analysis in Hong Kong identified a 3-fold increase in the incidence of CA-CDI cases, from $0.86 / 100,000$ population in 2006 to $2.96 / 100,000$ population in 2014 (6). These reports suggest that CA-CDI may be increasing worldwide; however, because the studies relied on retrospective extraction of data that were not specifically collected for CDI surveillance, they may be susceptible to misclassification and reporting biases (14).

The factors underlying this apparent increase in CA-CDI incidence are unclear. However, we hypothesize that this rise may result from any combination of the following: increased disease severity, leading to a greater proportion of case-patients being hospitalized; increased use of antimicrobial drugs or proton-pump inhibitors in the community; emergence of community-specific novel virulent $C$. difficile strains; and heightened awareness by physicians to consider the diagnosis of CDI.

Our study has many strengths. We used prospectively collected data from a well-established surveillance program enrolling virtually all per- sons admitted to acute-care hospitals in the province, thereby limiting selection bias, and we used standardized case definitions to avoid misclassification issues. However, our study also has several limitations. Only persons hospitalized with CACDI were reported to the surveillance program; therefore, milder cases were not captured. Thus, the actual incidence of CA-CDI may be underestimated. Because no clinical data regarding patients in whom CDI develops were collected, we cannot characterize patients or investigate potential changes in the affected population. We could not investigate the effect of diagnostic assay modifications on the observed change in trend because this information was not collected. Nucleic acid amplification tests are more sensitive than enzyme immunoassays for detecting toxigenic $C$. difficile; thus, increased use of these tests could lead to increased CA-CDI incidence rates. However, use of a more sensitive assay would be expected to affect CA-CDI and HA-CDI incidence similarly, whereas these trends are clearly divergent.

In conclusion, CA-CDI incidence in the province of Quebec increased significantly during 2008-2015 despite an overall decrease in HA-CDI incidence. This divergence in trends suggests a need to devote more attention to CA-CDI.

Table 2. Segmented regression of HA-CDI and CA-CDI in the province of Quebec, Canada, 2008-2015

\begin{tabular}{|c|c|c|c|c|c|c|}
\hline \multirow[b]{2}{*}{ Rate } & \multicolumn{2}{|c|}{$2008-2009$ to $2010-2011$} & \multicolumn{4}{|c|}{$2011-2012$ to $2014-2015$} \\
\hline & $\begin{array}{l}\text { Overall trend before } \\
\text { the breakpoint, IRR } \\
(95 \% \mathrm{Cl})\end{array}$ & $p$ value & $\begin{array}{l}\text { Immediate change } \\
\text { after the breakpoint, } \\
\text { IRR }(95 \% \mathrm{Cl})\end{array}$ & $p$ value & $\begin{array}{c}\text { Change in trend after } \\
\text { the breakpoint, IRR } \\
(95 \% \mathrm{Cl})\end{array}$ & $p$ value \\
\hline $\begin{array}{l}\text { HA-CDI rate/10,000 patient- } \\
\text { days }\end{array}$ & $1.003(1.001-1.005)$ & 0.001 & $0.998(0.945-1.053)$ & 0.93 & $0.996(0.994-0.998)$ & 0.001 \\
\hline $\begin{array}{l}\text { CA-CDI rate } / 100,000 \\
\text { population }\end{array}$ & 1.007 (1.003-1.012) & 0.002 & $0.95(0.841-1.074)$ & 0.41 & $0.997(0.992-1.002)$ & 0.30 \\
\hline Group difference & $1.002(0.997-1.007)$ & 0.35 & $0.971(0.851-1.107)$ & 0.66 & $1.002(0.996-1.008)$ & 0.53 \\
\hline
\end{tabular}




\section{Acknowledgement}

We thank the hospitals that participated in the prospective surveillance program.

Funding was provided by the Institut National de Santé Publique du Québec.

\section{About the Author}

Dr. Zanichelli is an infectious disease physician working as a research assistant at the Lady Davis Institute for Medical Research in Montreal, Canada. Her current research focuses on CDIs and antibiotic stewardship in the inpatient setting.

\section{References}

1. Levy AR, Szabo SM, Lozano-Ortega G, Lloyd-Smith E, Leung V, Lawrence R, et al. Incidence and costs of Clostridium difficile infections in Canada. Open Forum Infect Dis. 2015;2:ofv076. https://doi.org/10.1093/ofid/ofv076

2. Loo VG, Poirier L, Miller MA, Oughton M, Libman MD, Michaud S, et al. A predominantly clonal multi-institutional outbreak of Clostridium difficile-associated diarrhea with high morbidity and mortality. N Engl J Med. 2005;353:2442-9. https://doi.org/10.1056/NEJMoa051639

3. Institut National de Santé Publique du Québec (INSPQ). Surveillance provinciale des diarrhées à Clostridium difficile (DACD)-typage des souches de C. difficile causant la DACD au Québec, 2005-2015 [cited 2018 Nov 26]. https://www.inspq.qc.ca/publications/2444

4. Kotila SM, Mentula S, Ollgren J, Virolainen-Julkunen A, Lyytikäinen O. Community- and healthcare-associated Clostridium difficile infections, Finland, 2008-2013. Emerg Infect Dis. 2016;22:1747-53. https://doi.org/10.3201/ eid2210.151492

5. Reveles KR, Pugh MJV, Lawson KA, Mortensen EM, Koeller JM, Argamany JR, et al. Shift to community-onset Clostridium difficile infection in the national Veterans Health Administration, 2003-2014. Am J Infect Control. 2018; 46:431-5. https://doi.org/10.1016/j.ajic.2017.09.020

6. Ho J, Dai RZW, Kwong TNY, Wang X, Zhang L, Ip M, et al. Disease burden of Clostridium difficile infections in adults, Hong Kong, China, 2006-2014. Emerg Infect Dis. 2017;23:1671-9. https://doi.org/10.3201/eid2310.170797
7. Institut National de Santé Publique du Québec (INSPQ). Surveillance des diarrhées à Clostridium difficile (DACD) [cited 2018 Nov 18]. https:// www.inspq.qc.ca/ infections-nosocomiales/spin/dacd

8. Institut de la Statistique du Québec. Le bilan démographique du Québec, édition 2017 [cited 2018 Nov 26]. http:/ / www. stat.gouv.qc.ca/statistiques/population-demographie/ bilan2017.pdf

9. Institut National de Santé Ppublique du Québec (INSPQ). Surveillance provinciale des diarrhées à Clostridium difficile au Québec protocole [cited 2018 Nov 19]. https://www.inspq.qc.ca/sites/default/files/documents/ infectionsnosocomiales/protocole_dacd_2018.pdf

10. Bogaty C, Lévesque S, Garenc C, Frenette C, Bolduc D, Galarneau LA, et al.; Quebec Clostridium difficile Infection Surveillance Program (QCISP). Trends in the use of laboratory tests for the diagnosis of Clostridium difficile infection and association with incidence rates in Quebec, Canada, 2010-2014. Am J Infect Control. 2017;45:964-8. https://doi.org/10.1016/j.ajic.2017.04.002

11. Wagner AK, Soumerai SB, Zhang F, Ross-Degnan D. Segmented regression analysis of interrupted time series studies in medication use research. J Clin Pharm Ther. 2002;27:299-309. https:// doi.org/10.1046/j.1365-2710. 2002.00430.x

12. Katz KC, Golding GR, Choi KB, Pelude L, Amaratunga KR, Taljaard M, et al.; Canadian Nosocomial Infection Surveillance Program. The evolving epidemiology of Clostridium difficile infection in Canadian hospitals during a postepidemic period (2009-2015). CMAJ. 2018;190:E758-65. https://doi.org/10.1503/cmaj.180013

13. Jen MH, Saxena S, Bottle A, Pollok R, Holmes A, Aylin P. Assessment of administrative data for evaluating the shifting acquisition of Clostridium difficile infection in England. J Hosp Infect. 2012;80:229-37. https:/ / doi.org/ 10.1016/j.jhin.2012.01.001

14. Albert K, Ross B, Calfee DP, Simon MS. Overreporting healthcare-associated $C$. difficile: a comparison of NHSN LabID with clinical surveillance definitions in the era of molecular testing. Am J Infect Control. 2018;46:998-1002. https://doi.org/10.1016/j.ajic.2018.03.001

Address for correspondence: Yves Longtin, Rm E-0057, Infection Prevention and Control Unit, Jewish General Hospital SMBD, 3755 Côte-Sainte-Catherine Rd, Montreal, QB H3T 1E2, Canada; email: yves.longtin@mcgill.ca 